\title{
Peran Wanita Pedagang Sayur Terhadap Perekonomian Keluarga Di Pasar Pagi Desa Sumowono Kabupaten Semarang
}

\author{
(The Role Of Women Of Vegetable Traders In Supporting The Family Economy Morning \\ Market Sumowono Village,Semarang Regency)
}

\author{
Noviya Endang Lestari", Dyah Mardiningsih, dan Wulan Sumekar \\ Program Studi Agribisnis, Departemen Pertanian, Fakultas Peternakan dan Pertanian \\ Universitas Diponegoro \\ "Penulis korespondensi: noviyaendanglestari@gmail.com
}

\begin{abstract}
ABSTRAK
Penelitian ini bertujuan untuk 1) menganalisis peran wanita pedagang sayur dalam perekonomian keluarga dengan menggunakan pendapatan sebagai parameternya. 2) menganalisis pembagian peran berdasarkan gender 3 ) menganalisis curahan waktu kerja wanita pedagang sayur 4) akses dan kontrol wanita pedagang sayur di dalam keluarga. Penelitian ini dilaksanakan pada Bulan Desember 2018 di Pasar Pagi Desa Sumowono Kabupaten Semarang. Metode yang digunakan pada penelitian ini adalah survai. Metode penentuan sampel menggunakan purposive sampling dengan jumlah responden 34 orang pedagang dengan kriteria 1) pedagang sayur berjenis kelamin perempuan. 2) pedagang sayur memiliki suami yang masih aktif bekerja. 3) pedagang sayur tidak dibantu orang karyawan dalam bekerja 4) khusus menjual sayuran hasil pertanian 5) tidak memiliki pekerjaan lain di sektor produktif. Analisis data secara deskriptif kuantitatif. Hasil penelitian menunjukan bahwa Sumbangan yang diberikan wanita pedagang sayur didalam perekonomian keluarga adalah $51,79 \%$. Pembagian peran berdasarkan gender pada sektor reproduktif yang terjadi pada lokasi penelitian didominasi oleh wanita pedagang sayur. Wanita pedagang sayur rata rata bekerja pada sektor Produktif selama 6 jam 7 menit per hari, atau sebesar $28 \%$. Curahan waktu wanita pedagang sayur untuk pada sektor Reproduktif adalah sebesar 38\% atau rata-rata selama 9 jam 11 menit per hari. Akses dan kontrol wanita pedagang sayur di dalam keluarga juga tidak terbatas dalam memutuskan penggunaan uang untuk dapat memenuhi kebutuhan keluarga.
\end{abstract}

Kata Kunci : Wanita, pedagang sayur, perekonomian keluarga

\section{ABSTRACT}

This study aims to 1) analyze the role of female vegetable traders in the family economy by using income as a parameter. 2) analyze the division of roles based on gender 3) analyze the outpouring of working time for women vegetable traders 4) access and control of vegetable sellers in the family. This research was conducted in December 2018 at the Morning Market in Sumowono Village, Semarang Regency. The method used in this study is survey. The method of determining the sample using purposive sampling with the number of respondents 34 traders with criteria 1) vegetable traders are female. 2) Vegetable traders have husbands who are still actively working. 3) Vegetable traders are not assisted by employees when working 4) specifically sell vegetables from agricultural products 5) do not have other jobs in the productive sector. Descriptive quantitative data analysis. The results showed that the contribution given by women vegetable traders in the family economy was $51.79 \%$. The division of roles based on gender in the reproductive sector that occurred at the study site was dominated by vegetable traders. The average female vegetable trader works in the Productive sector for 6 hours 7 minutes per day, or $28 \%$. The time spent for women vegetable traders for the Reproductive sector is $38 \%$ or an average of 9 hours 11 minutes perday. Access and control of vegetable sellers in the family is also not limited in deciding the use of money to meet family needs.

Keywords: Women, vegetable traders, family economy

Noviya Endang Lestari", Dyah Mardiningsih, dan Wulan Sumekar : Peran Wanita Pedagang Sayur Terhadap Perekonomian Keluarga 


\section{PENDAHULUAN}

Keluarga merupakan unit terkecil dari masyarakat yang terdiri dari kepala keluarga, dan beberapa orang yang berkumpul tinggal disuatu tempat dibawah satu atap dalam keadaan saling ketergantungan (Efendy,2005). Kepala keluarga bertanggung jawab untuk memenuhi kebutuhan bagi keluarga, namun beberapa faktor menyebabkan kepala keluarga tidak mampu memenuhi kebutuhan keluarganya. Menurut BPS Kabupaten Semarang tahun 2017 di Kecamatan Sumowono masih ada keluarga yang belum bisa memenuhi kebutuhanya yaitu sebanyak 2.692 dari jumlah total 10.376 keluarga. Pendapatan kepala keluarga yang rendah menyebabkan banyak istri ikut bekerja demi tercukupinya kebutuhan.

Pasar Pagi Desa Sumowono merupakan salah satu pasar di Kabupaten Semarang yang terletak di Kecamatan Sumowono. Pelaku yang berperan dalam perdagangan di Pasar Sumowono sebagian besar adalah wanita. Kecamatan Sumowono dikenal luas di kalangan penduduk Jawa Tengah karena merupakan kawasan penghasil sayur mayur, bunga-bungaan, buahbuahan, dan aneka hasil perkebunan seperti kopi, vanili, dan pala.

Pedagang sayur wanita di Pasar Pagi Desa Sumowono bekerja untuk membantu memenuhi kebutuhan keluarga. Kondisi pendapatan keluarga yang kurang, dan tingkat pendidikan yang rendah menjadi faktor pendorong yang kuat bagi istri untuk bekerja sebagai pedagang sayur. Badan Pusat Statistik di Kabupaten Semarang menunjukan bahwa jumlah penduduk wanita pada tahun 2017 yaitu 409.682, dimana sebanyak 278.699 wanita bekerja. Hal tersebut menunjukan bahwa lebih dari $50 \%$ penduduk wanita di Kabupaten Semarang bekerja di sektor produktif . Berkaitan dengan pengerahan sumber daya ekonomi dalam keluarga telah menuntut wanita untuk ikut serta menopang kebutuhan keluarga, meskipun itu bukan tanggung jawabnya.

Umumnya Ibu Rumah hanya bertanggung jawab dalam urusan reproduktif, namun dalam kondisi tertentu seorang ibu harus rela ikut berperan di sektor ekonomi (Farida, 2011). Peran wanita menjadi sangat penting, bukan hanya menjadi pengatur pemasukan dan pengeluaran kebutuhan pokok, tapi juga menambah pemasukan bagi perekonomian keluarganya. Peran wanita menjadi ganda, dengan mengurus segala keperluan keluarga, ditambah lagi bekerja menjadi pedagang sayur semata-mata untuk menambah penghasilan keluarga. Anggapan pada masyarakat bahwa bahwa kaum wanita bersifat lemah lembut, memelihara, dan tidak cocok sebagai kepala keluarga, akibatnya semua pekerjaan domestik menjadi tanggung jawab wanita. Peran ganda yang dilakukan oleh wanita menjadikan beban kerja wanita lebih berat daripada laki-laki. Pekerjaan yang dilakukan oleh wanita pedagang sayur membutuhkan alokasi waktu yang dicurahkan untuk dapat menyelesaikan pekerjaan tersebut.

Suami sebagai kepala rumah tangga adalah sebagai panutan menentukan arah dantujuan rumah tangga, namun tidak dipungkiri ketika peran antara suami dan istri saling melengkapi untuk pengambilan keputusan rumah tangga. Akses dan kontrol di dalam keluarga diperlukan untuk mengeloa dan memanfaatkan sumber daya yang ada pada keluarga dan menentukan kebijakan dan pengambilan keputusan antara lakilaki dan perempuan (Farihah, 2015).

\section{METODE PENELITIAN}

Penelitian ini dilaksanakan pada bulan November - Desember 2018 yang berlokasi di Pasar Sumowono yang terletak di Jalan Jendral Sudirman No. 2-4 Sumowono Kabupaten Semarang. Lokasi tersebut dipilih secara sengaja karena di 
Pasar Pagi Desa Sumowono merupakan tempat para pedagang sayur keliling membeli dagangan dipagi hari dan sebagian besar pedagang sayur di pasar tersebut adalah wanita.

Metode penelitian ini menggunakan metode survei. Teknik pengambilan data melalui wawancara dengan kuesioner. Metode survai merupakan metode untuk memperoleh fakta-fakta dari gejala-gejala yang ada dan mencari keterangan secara faktual baik mengenai institusi sosial, ekonomi, politik dari suatu kelompok ataupun daerah dalam waktu bersamaan terhadap individu maupun unit, baik itu secara sensus ataupun dengan sample (Nazir, 2013). Tujuan dari penggunaan metode survai yaitu untuk mendapatkan fokus yang ingin didapatkan sesuai dengan kuesioner yang diajukan dan bertujuan untuk dapat digeneralisasikan untuk objek yang sebagian keadaan sosialnya sama. Metode survai digunakan dengan pengamatan langsung, dengan melalui pedoman wawancara serta kuesioner (Sutiyono, 2013).

Responden diambil dengan menggunakan teknik Purposive sampling. Teknik Purposive sampling merupakan teknik pengambilan sampel yang berdasarkan atas suatu pertimbangan tertentu seperti sifat-sifat populasi ataupun ciri - ciri yang sudah diketahui sebelumnya (Notoatmodjo, 2010). Penelitian ini mengambil 34 orang dari keseluruhan populasi pedagang sayur yaitu sebanyak 56 pedagang. Populasi adalah wilayah generalisasi yang terdiri atas objek / subjek yang mempunyai kualitas dan karakteristik tertentu yang ditetapkan oleh peneliti untuk dipelajari dan kemudian ditarik kesimpulan (Sujarweni dan endaryanto, 2012 ). Kriteria yang telah ditentukan pada penelitian ini, diantaranya:

1. Pedagang sayur berjenis kelamin wanita,

2. Pedagang sayur masih memiliki suami yang masih aktif bekerja.

3. Tidak dibantu oleh karyawan dalam bekerja.

4. Khusus menjual sayuran hasil pertanian.

5. Tidak memiliki pekerjaan lain disektor produktif.

Data yang digunakan dalam penelitian ini merupakan data primer dan data sekunder. Data primer diperoleh dari hasil wawancara langsung terhadap responden, dengan menggunakan kuesioner. Data sekunder yang diperoleh dari hasil studi pustaka yaitu dengan mencari data dari buku, jurnal, maupun dinas terkait.

\section{HASIL DAN PEMBAHASAN Karakteristik Responden}

\section{Usia}

Berdasarkan Penelitian dapat diketahui bahwa hampir seluruh pedagang sayur di Pasar pagi Desa sumowono berada pada usia produktif, dimana sebanyak $94,1 \%$ berada pada usia 25-60 tahun. Hal ini sesuai dengan pendapat yang dikemukakan oleh mulyadi (2012) yang menyatakan bahwa usia produktif tenaga kerja adalah 15-64 tahun. Usia akan mempengaruhi produktifitas seseorang dalam bekerja. Hal ini sesuai dengan pendapat yang dikemukakan oleh Mahendra dan Woyanti (2014) yang menyatakan bahwa salah satu faktor yang mempengaruhi produktifitas tenaga kerja adalah usia.

\section{Tingkat Pendidikan}

Pekerjaan sebagiai pedagang sayur merupakan pekerjaan yang tidak memerlukan keahlian khusus maka kebanyakan pendidikan para wanita pedagang sayur ini rendah. Pendidikan wanita pedagang sayur paling banyak hanya sampai SD dengan persentase $52,9 \%$.

\section{Lama Bekerja}


Masyarakat perkampungan Lama bekerja wanita pedagang sayur paling banyak antara 1-5 tahun yaitu sebanyak 17 pedagang. Lama bekerja merupakan salah satu faktor yang mempengaruhi produktivitas kerja, semakin lama masa kerja seseorang, maka keterampilan dan kemampuan seseorang dalam bekerja akan semakin meningkat. Hal ini sesuai dengan pendapat yang dikemukakan oleh Pamungkas et,al (2017) yang menyatakan bahwa faktor-faktor yang mempengaruhi produktifitas seseorang dalam bekerja adalah lama bekerja. Semakin lama seseorang bekerja maka pengalamannya semakin banyak.

\section{Curahan Waktu Kerja Wanita Pedagang sayur \\ Produktif}

Curahan waktu kerja sektor produktif dapat dilihat pada tabel 2.

Tabel 1. Curahan Waktu Kerja Produktif

\begin{tabular}{ccccc}
\hline \hline Membeli Dagangan & $\begin{array}{c}\text { Menyiapkan } \\
\text { dagangan }\end{array}$ & Jualan & $\begin{array}{c}\text { Perjalanan Ke } \\
\text { pasar PP }\end{array}$ & $\begin{array}{c}\text { Jumlah Curahan } \\
\text { Waktu }\end{array}$ \\
\hline \multicolumn{5}{c}{ pan----Jam----- } \\
\hline 1 & 3,1 & 0,25 & 6,7 \\
\hline
\end{tabular}

Sumber: Data primer diolah 2019

Waktu yang dibutuhkan oleh wanita pedagang sayur untuk berjualan rata-rata adalah selama 6 jam 7 menit. Wanita pedagang sayur mulai berangkat ke pasar pukul 00.00 tengah malam sampai pukul 04.00 dini hari, mereka berjualan pada dini hari karena melayani pembeli yang sebagian besar bahkan hampir semua pembeli adalah pedagang sayur keliling yang dimana pedagang sayur keliling membeli dagangangan pada dini hari dikarenakan mereka menjual dagangannya ke keliling pada pagi hari. Wanita pedagang sayur membeli dagangan pada sore hari sekitar pukul 15.00-17.00. Dagangan yang dijual dibeli dari petani langsung maupun pedagang besar, kemudian akan dijual lagi oleh pedagang sayur pada dini hari.

\section{Pendapatan Keluarga Perbulan}

Tabel 2. Pendapatan Keluarga Wanita Pedagang Sayur

\begin{tabular}{lcc}
\hline \hline & \multicolumn{2}{c}{ Pendapatan Keluarga/Bulan } \\
\hline Suami & 2.182 .000 & $45,46 \%$ \\
Istri & 2.447 .000 & $51,79 \%$ \\
Anak & 138.000 & $2,75 \%$ \\
\hline Rata-rata & 4.767 .000 & $100,00 \%$ \\
\hline Sumber: Data primer diolah 2019 & &
\end{tabular}

Berdasarkan penelitian yang telah dilakukan dapat diketahui bahwa pendapatan keluarga diperoleh dari sumbangan suami didalam keluarga, sumbangan istri didalam keluarga, dan sumbangan anak didalam keluarga. Sumbangan terbesar pada perekonomian keluarga merupakan sumbangan dari istri yaitu sebesar $51,79 \%$ kemudian suami sebesar $45,46 \%$ dan yang terakhir adalah sumbangan anak sebesar $2,75 \%$.

\section{Curahan Waktu Kerja Reproduktif} Hasil penelitian menunjukan bahwa waktu yang dicurahkan wanita 
pedagang sayur pada sektor rumah tangga (Reproduktif) adalah sebesar $38 \%$ atau rata - rata selama 9 jam 11 menit per hari. Jumlah curahan kerja reproduktif wanita pedagang sayur lebih besar dibandingan dengan waktu yang dicurahkan pada sektor produktif, berarti wanita pedagang sayur meskipun bekerja namun masih bisa menjalankan perannya sebagai ibu rumah tangga dan tidak mengganggu kegiatan keluarga sehingga wanita pedagang bisa menghasilkan uang tanpa mengesampingkan tanggung jawabnya sebagai ibu rumah tangga. Selain itu pekerjaan tersebut dilakukan dini hari dan tidak ada sifat pemaksaan waktunya, sehingga mereka dapat bekerja sesuai dengan kemauanya sendiri sehingga jika dirasakan ada pekerjaan penting dirumah atau keperluan lainnya maka pekerjaan tersebut bisa ditinggal.

\section{Pembagian Peran Berdasarkan Gender Dalam Keluarga \\ Pembagian peran dalam} keluarga wanita pedagang sayur terdiri dari pembagian peran pada sektor reproduktif dan sosial masyarakat.

\section{Pembagian Peran Sektor Reproduktif \\ Dominasi perempuan pada} semua sektor reproduktif didasari oleh pemikiran masyarakat dilokasi penelitian yang masih menganut pemahaman bahwa seorang istri sudah selayaknya mengerjakan pekerjaan rumah tangga. Hal tersebut mencerminkan bahwa sebagian besar wanita di pasar desa sumowono masih memegang erat prinsip bahwa perempuan pada hakekatnya bertugas untuk memelihara keutuhan rumah tangga dan sebagai pemegang tugas dalam mengurus pekerjaan rumah tangga. Wanita pedagang sayur masih sangat menghormati kedudukan suami yaitu sebagai pemimpin keluarga dan rumah tangga. Mereka mengganggap bahwa pekerjaan suami hanyalah mencari nakah untuk keluarganya sehingga pada lokasi penelitian terlihat bahwa peran antara suami dan istri sangat berbeda.

\section{Pembagian Peran Sosial Masyarakat}

Kegiatan sosial kemasyarakatan yang dilakukan oleh keluarga wanita pedagang sayur meliputi menghadiri rapat desa, dalam menghadiri acara rapat desa sebanyak 32 keluarga dilakukan oleh suami dengan persentase sebanyak $94,1 \%$ dan 2 keluarga lainya dilakukan bersama-sama antara suami dan istri dengan persentase sebesar 5,9\%, menghadiri kerja bakti yang dilakuakan oleh suami sebanyak 30 keluarga dengan persentase sebesar $88,2 \%$ dan 4 keluarga lainya dilakukan secara bersama-sama antara suami dan istri dengan persentase sebanyak $11,8 \%$, menghadiri acara hajatan dilakukan secara bersama-sama pada seluruh keluarga wanita pedagang sayur antara suami dan istri dengan persentase sebesar $100 \%$, serta menghadiri acara tetangga juga dilakukansecara bersama sama antara suami dan istri pada seluruh keluarga wanita pedagang sayur dengan persentase sebesar 100\%yaitu 34 keluarga. Hal ini diakui oleh wanita pedagang sayur yang menyatakan bahwa kegiatan menghadiri acara tetangga dan hajatan merupakan kepetingan bersama sehingga dilakukan bersama-sama antara suami dan istri.

\section{Akses Ekonomi Wanita Pedagang Sayur Dalam Keluarga}

Akses yang dimaksudkan dalam penelitian ini merupakan hak seorang istri untuk mendapatkan kesempatan dalam memperoleh dan mengelola ekonomi keluarga serta akses terhadap kredit. Hal ini sesuai dengan pendapat yang dikemukakan oleh widodo (2009) yang menyatakan bahwa pengelolaan keuangan rumah tangga merupakan peranan yang paling menonjol bagi wanita 
sebagai seorang istri dan bertanggung jawab pada proses keuangan yang dimulai dari penyimpanan hingga pengaturan kebutuhan sehari-hari.

Tabel 3. Akses Keluarga Wanita Pedagang sayur

\begin{tabular}{lcc}
\hline \hline & Akses & \\
\hline & Suami & Istri \\
\hline Menyimpan Pendapatan & $\mathrm{R}$ & $\mathrm{T}$ \\
Memperoleh Pinjaman & $\mathrm{T}$ & $\mathrm{T}$ \\
Mengelola Pendapatan & $\mathrm{R}$ & $\mathrm{T}$ \\
\hline
\end{tabular}

Hasil penelitian menunjukan bahwa wanita pedagang sayur di pasar pagi desa Sumowono memiliki akses dalam perekonomian keluarga. Peran wanita dalam mengakses ekonomi keluarga cukup tinggi mengenai bagaimana wanita menyimpan pendapatan keluarga, mendapatkan pinjaman demi ekonomi keluarga, serta

\section{Kontrol Wanita Pedagang Sayur terhadap Ekonomi Keluarga}

Tabel 4. Kontrol Keluarga Wanita Pedagang sayur

\begin{tabular}{lcc}
\hline \hline \multicolumn{1}{c}{ Pengambilan Keputusan } & Kontrol & \\
\hline Pangan harian & Suami & Istri \\
Kebutuhan pakaian & $\mathrm{R}$ & $\mathrm{T}$ \\
Kebutuhan sosial & $\mathrm{T}$ & $\mathrm{T}$ \\
Kebutuhan Kesehatan & $\mathrm{T}$ & $\mathrm{T}$ \\
Kebutuhan Sehari-hari & $\mathrm{T}$ & $\mathrm{T}$ \\
Kebutuhan Pendidikan & $\mathrm{T}$ & $\mathrm{T}$ \\
\hline
\end{tabular}

Sumber: Data primer diolah, 2019.

Keterangan: R (Rendah) T (Tinggi)

Wanita pedagang sayur memiliki kontrol yang tinggi dalan keikut sertaan pengambilan keputusan terutama masalah ekonomi keluarga di lokasi penelitian dimana sebagian wanita terlibat dalam pengambilan keputusan yang menyangkut dengan masalah ekonomi keluarga. Pola hubungan keluarga pada lokai penelitian merupakan pola demokratis dimana semua anggota keluarga memiliki hak untuk melakukan sesuatu, namun dengan kesepakatan bersama. Hal ini sesuai dengan pendapat yang dikemukakan oleh singgih et.al (1991) yang menyatakan bahwa seiring dengan perkembangan waktu pola antara hubungan suami dan istri bersifat demokratis dimana dalam pengambilan keputusan dalam keluarga, seorang suami memiliki kesadaran akan sikap demokratis.

\section{KESIMPULAN DAN SARAN \\ Kesimpulan}

Basarkan hasil penelitian yang telah diteliti maka dapat disimpulkan sebagai berikut:

1. Sumbangan yang diberikan wanita pedagang sayur didalam perekonomian keluarga adalah $51,79 \%$ dimana jumlah tersebut lebih besar jika dibandingkan dengan sumbangan yang diberikan oleh suami, dimana suami hanya menyumbangkan penghasilanya sebesar $45,46 \%$ dan sumbangan anak terhadap perekonomian keluarga sebesar $2,75 \%$. 
2. Pembagian peran berdasarkan gender pada sektor reproduktif yang terjadi pada lokasi penelitian didominasi oleh wanita pedagang. Anggapan dimasyarakat bahwa wanita tidak cocok menjadi kepala keluarga mengakibatkan semua sektor domestik menjadi tanggung jawab istri, meskipun istri telah menghasilkan uang. Wanita pedagang sayur di Pasar Desa Sumowono melakukan pekerjaan pada sektor produktif dan bertanggung jawab pula pada sektor reproduktif.

3. Wanita pedagang sayur rata-rata bekerja pada sektor (Produktif) selama 6 jam 7 menit per hari, atau sebesar $28 \%$. Curahan waktu wanita pedagang sayur untuk pada sektor rumah tangga (Reproduktif) adalah sebesar $38 \%$ atau rata-rata selama 9 jam 11 menit per hari.

4. Kesempatan dan akses istri dalam mengelola ekonomi keluarga sebagian besar memiliki akses yang tinggi.Wanita pedagang sayur memiliki hak dalam mengakses sumberdaya yang ada dalam keluarga, seperti menyimpan dan mengelola perekonomian didalam keluarga, bahkan istri sudah dianggap lebih mampu menjaga dan mengelola perekonomian degan baik apabila dibandingkan dengan suami. Wanita pedagang sayur mempunyai kesempatan yang sama untuk melakukan kontrol untuk memanfaatkan sumberdaya yang ada.Istri pun memiliki kontrol yang tinggi dalam memutuskan kebutuhankebutuhan yang diperlukan keluarga.

\section{Saran}

Anggapan dimasyarakat bahwa wanita tidak cocok menjadi kepala keluarga mengakibatkan semua sektor domestik menjadi tanggung jawab wanita, meskipun istri telah menghasilkan uang. Hal ini menjadikan Hendaknya didalam keluarga wanita pedagang sayur suami juga membantu pekerjaan istri dirumah, agar beban tugas istri tidak terlalu berat, dan waktu yang dicurahkan wanita untuk bekerja tidak berlebih.

\section{DAFTAR PUSTAKA}

Efendi,O. 2005. Ilmu Komunikasi Teori dan Praktek. Remaja Rosda karya, Bandung.

Farida, L. 2011. Kontribusi pendapatan perempuan bekerja sektor informal pada ekonomi keluarga dikota pekan baru. J. Aplikasi Bisnis. 1 (2) : 103-112. : 145 - 164.

Farihah, I. 2015. Etos kerja dan kuasa perempuan dalam keluarga : studi kasus keluarga nelayan di Brondong Lamongan jawa Timur. J. Palastren. 8 (1).

Mahendra,A. D., dan Woyanti, N . 2014. Analisis Pengaruh Pendidikan, Upah, Jenis Kelamin, Usia dan Pengalaman Kerja Terhadap Produktivitas tenaga kerja ( Studi industri Kecil Tempe di Kota Semarang). Doctoral Dissertation, Fakultas Ekonomika dan Bisnis, Universitas Diponegoro, Semarang.

Mulyadi. 2012. Akuntansi Biaya. Edisi Ke5. Cetakan kesebelas. STIM: Yogyakarta.

Nazir, M. 2013. Metode apenelitian Cetakan Kedelapan. Bogor : Ghalia Indonesia.

Notoatmodjo,S. 2010 . Metodologi Penelitian Kesehatan. Rienka Cipta: Jakarta 
Sugiyono.2011. Metode Penelitian Kuantitatif Kualitatif dan RD. Alfabeta: bandung.

Sujarweni,V. W., dan Endaryanto,P. 2012. Statistika Untuk Penelitian. Graha IImu: Yogyakarta.
Sutiyono. 2013 . Metode Penelitian Survey dan Korelasi. UPT Pendidikan Kecamatan Kebog, Dinas Pendidikan Pemuda dan Olahraga Kabupaten Kudus Provinsi Jawa Tengah.

Widodo, S. 2009. Analisis peran perempuan dalam usahatani Tembakau . J. Embrhyo. 6(2) : $148-153$. 